\title{
Determining the Effectiveness of Optimal Time-Varying Hedge Ratios for Cattle Feeders under Multiproduct and Single Commodity Settings
}

Hernan A Tejeda and Dillon M. Feuz - Agricultural Finance Review, 2014.

Purpose

Optimal multiproduct time-varying hedge ratios not only take into account the changing relationship of the spot and futures prices of commodities through time, but likewise the dynamic inter-relationship among prices from related factors of a production setting. The purpose of this article is to determine and contrast the risk mitigating effectiveness from optimal multiproduct time-varying hedge ratios, applied to the margin of a cattle feedlot operation, over single commodity time-varying and naive hedge ratios.

\section{Design/methodology/approach}

A parsimonious regime-switching dynamic correlations (RSDC) model is estimated in twostages, where the dynamic correlations among prices of numerous commodities vary proportionally between two different regimes/levels. This property simplifies estimation methods for a large number of parameters involved.

\section{Findings}

There is significant evidence that resulting simultaneous correlations among the prices of a commodity (e.g. live cattle spot and live cattle futures) reach different levels along the timeseries. Second, for in and out-of-sample data there is a substantial reduction in the operation's margin variance provided from (both) multiproduct and single time-varying optimal hedge ratios over naive hedge ratios. Lastly, risk mitigation is attained at a lower cost given that average optimal multiproduct and single time-varying hedge ratios obtained for corn, feeder cattle and live cattle - using either in or out-of-sample data - are significantly below the naive full hedge ratio.

\section{Research limitations}

A limitation of the framework implemented in the study is that once the hedge position is set, it is not possible to modify or update the hedge position in the following period.

\section{Practical Implications}

Feedlot operators and related industries will benefit from the potential implementation of this parsimonious RSDC model for their hedging operations (in futures markets), as it provides 
average optimal hedge ratios significantly lower than one and a sizeable advantages in margin risk mitigation.

\section{Originality}

This paper illustrates significant benefits attained from applying time-varying optimal hedge ratios in the context of a multi-product setting, in this case a cattle feedlot operation, over naive hedge ratios. Thus incorporating the dynamic time element, as well as the inter-relationships among commodities (with futures market presence) from a common production setting, substantially strengthens the risk management strategy.

Key Words: multiproduct optimal hedging, time-varying hedge ratios, feedlot operators, regimeswitching models 


\section{Introduction}

Agricultural crop markets have been experiencing substantial changes in their prices and volatility during the past decade, driven both by supply side factors such as unexpected severe weather conditions (droughts, floods), and by demand side factors in the form of unanticipated new economic conditions. Risk management tools that make use of financial instruments may facilitate mitigating the effect from these unexpected price swings through effective hedging. Production settings where inputs and outputs are exchanged in futures markets permit the application of multiproduct optimal hedging. This strategy takes into account a multivariate portfolio approach that potentially decreases risk more effectively than if applying single commodity hedging.

Early work by Anderson and Danthine (1980) presented the theoretical ground for an optimal multiproduct static scenario, where the hedge between multiple contracts in an efficient market responds to the covariance between the future and cash prices and the variance of the future prices. Later studies by Myers and Thompson (1989) and Baillie and Myers (1991) argued that optimal hedge ratios preferably required up-to-date information for estimating the variance and covariance of spot and futures prices, and thus determining dynamic optimal hedge ratios. This article determines time-varying (accounting for up-to-date information) hedge ratios in a multiproduct setting - a cattle feedlot operation - by applying a regime switching model of dynamic correlations (RSDC) to the multivariate series. The study uses a parsimonious RSDC model (Pelletier, 2006), identifying two different correlations regimes among pairs of prices, with the switch between regimes being governed by a Markov chain.

A broad review encompassing the development of theoretical foundations and the implementation of empirical frameworks and models for estimating optimal hedge ratios is 
provided by Lien and Tse (2002). Multivariate models have been extensively applied in the financial field to estimate optimal hedge ratios. Park and Switzer (1995) estimated optimal timevarying hedge ratios for three stock index futures, including S\&P 500, by using a bivariate (accounting for dynamic spot and futures prices) co-integration structure within a GARCH model (Bollerslev, 1988), finding substantial hedging improvement over constant (OLS) hedging methods. Choudhry (2004) finds that time-varying hedge ratios using a diagonal VECH for correlations in a bivariate GARCH framework (Bollerslev et al., 1988) outperform traditional hedging strategies for Australia, Hong-Kong and Japan stock futures markets. Lien and Yang (2006) investigate the effects of spot-futures spread on returns of several major currencies and their impact on hedging strategies, by using a bivariate dynamic conditional correlation (DCC) framework (Engle, 2002). Results identify substantial improvements over naive hedging strategies.

Studies accounting for simultaneous multivariate relationships among various price indices for hedging strategies include Hammoudeh et al. (2010) who determine the hedging effectiveness of various multivariate GARCH models, including the DCC, applied to four major precious metals. Best results are obtained with the DCC model. A study by Zanotti et al. (2010) applied to three major European electric markets arrive at similar results. Ji and Fan (2011) apply a multiproduct portfolio hedging strategy to energy markets, including crude oil, heating oil and gasoline, using a modified DCC model that incorporates an error correction framework (DCCECM_MVGARCH). Hedging effectiveness gains are obtained with the model in comparison to naïve or bivariate GARCH models.

Prior multiproduct hedge studies applied to a feedlot operation or a soybean complex incorporated some form of time-variant conditions. These include Peterson and Leuthold (1987), 
Tzang and Leuthold (1990), Fackler and McNew (1993), Garcia et al. (1995), and Manfredo et al. (2000). The latter two studies used a multivariate GARCH model (Bollerslev, 1990), which has the drawback of constraining the conditional covariance (or correlation) estimate of the matrix of cash and futures prices to be positive semi-definite (PSD) for each period. Garcia et al. (1995) circumvented this estimation complexity - intensified for a larger number of parameters being estimated - by applying a constant (conditional) correlation. Manfredo et al. (2000) used a Risk Metrics procedure, with a moving-average, for the time-varying covariance matrix. Optimal findings were of modest improvement over single commodity hedging. A study by Collins (2000) applied out of sample data (60 months of average futures and cash prices) to the estimated optimal hedge ratios from multiproduct hedging studies by Tzang and Leuthold (1990) and Fackler and McNew (1993) - which used monthly average price data, and found no significant benefits of multiproduct optimal hedge ratios over naive (1:1) hedging.

Haigh and Holt (2000) apply a BEKK MGARCH (Engle and Kroner, 1995) model for multiproduct hedging of wheat, soybeans and international freight rates, finding gains in reducing price variability in international grain trade for out-of-sample data. Noussinov and Leuthold (1999) study multiproduct hedging in a feedlot operation setting, yet they do not apply time-varying correlations to estimate optimal hedge ratios. Conversely, Sephton (1993) estimates single time-varying hedge ratios for wheat feed, barley feed and canola from Canada using a bivariate GARCH model, with constant conditional correlations, and finds improved performance over traditional (OLS) strategies. Bera et al. (1997) estimate single time-varying hedge ratios for corn and soybean, applying a diagonal VECH for correlations in the bivariate GARCH model, finding hedging improvement over the constant correlation bivariate GARCH models. More recently, Choudhry (2009) compares four different bivariate GARCH models in 
estimating single time-varying hedge ratios of several agricultural commodities, finding moderate hedging improvement from the GARCH-X (Lee, 1994) model. Park and Jei (2010) estimate (bivariate) single time-varying hedge ratios for corn and soybeans using the dynamic conditional correlations (DCC) model, and find a small improvement over unconditional (OLS) hedging strategy. Bekkerman (2011) applies the DCC model in a multiproduct setting to estimate time-varying hedge ratios of linked wheat markets in Montana, finding improvements over single market-bivariate hedge ratios. Both of these cases estimate a time-varying, conditional covariance (correlation) matrix, of similar form to the RSDC model.

A study by Alizadeh and Nomikkos (2004) applies regime-switching models, governed by a Markov chain, to estimate optimal time-varying hedge ratios for FTSE 100 and S\&P 500. Results obtained are of improved hedging performance over bivariate GARCH and naive models. Lee and Yoder (2007) extend the BEKK-MGARCH model to a regime-switching bivariate BEKK model to estimate state-dependent time-varying optimal hedge ratios. Results of estimated optimal hedge ratios for corn and nickel are of moderate variance reduction improvement in comparison to regular BEKK or naive methods.

This study makes use of a parsimonious RSDC model (Pelletier, 2006), which considers a reduced number of parameters to estimate. A benefit of the parsimonious RSDC model is the estimation improvement over the DCC model for a large number of parameters, given that correlation changes across regimes are proportional to each other. Thus, the parsimonious model requires estimating (time-invariant) correlation parameters for one regime and the proportional factor(s) with which the correlation parameters at the other regime(s) will be obtained as the product of the estimated parameters and the factor(s) (Pelletier, 2006). For simplicity, the model 
estimates two different regimes, ${ }^{1}$ leaving the estimation of three or more for further study.

Results of estimated optimal dynamic multiproduct hedge ratios and dynamic single commodity hedge ratios - for a feedlot operation - indicate significant improvement over naive hedge ratios for in sample data, becoming a considerable improvement for out-of-sample data. Moreover, the average estimated optimal multiproduct hedge ratios are significantly below naive hedge ratios, thus requiring less than a full hedge and lowering hedging costs.

\section{Hedging Methodology}

The methodology applied to determine the time-varying hedge ratios is the mean-variance hedge ratio derived from Myers and Thompson (1989), similar to that derived by Brorsen et al. (1998) and Leuthold et al. (1989). The latter frameworks stem from the five assumptions considered by Benninga et al. (1984) to show that the mean-variance hedge ratios developed by Johnson (1960) are likewise consistent with utility maximizing hedge ratios. Let an agent take a spot and futures position at period $t-1$, then the agent's profit at liquidation $t$ is

$\pi_{t}=p_{t} q_{t-1}-c\left(q_{t-1}\right)-\left(f_{t}-f_{t-1}\right) b_{t-1}$

where $\pi_{t}$ is profit, $p_{t}$ is the spot price in period $t, q_{t-1}$ is the spot position chosen at $t-1, c$ is an increasing and convex cost function, $f_{t}$ is the futures price quoted at period $t$ for delivery at some future date, and $b_{t-1}$, is sales of futures contracts in $t-l$ (purchases if negative). Allowing for stochastic production yields an agent that chooses $q_{t-1}$ and $b_{t-1}$ that maximizes a linear function of the mean and variance of profit, conditional on available information at $t-1$.

\footnotetext{
${ }^{1}$ Pelletier (2006) estimates up to three different regimes of dynamic correlations among four exchange rates, and finds that the likelihood ratio (LR) improvement over a model with two regimes is less than $1 \%$. The downside being the larger number of parameters estimated
} 
First order conditions for optimization are applied by differentiating with respect to the spot position and sales of futures contracts, and equaling to zero (Myers and Thompson, 1989). General assumptions are applied (Brorsen et al., 1998) i.e., given an agent's specific risk aversion level, non-existing transactions costs, and unbiased futures market; the resulting equations are thus simplified and the optimal hedge ratio $\left(r^{*}\right)$ becomes:

$r^{*}=\frac{b_{t-1}}{q_{t-1}}=\frac{\sigma_{s f}}{\sigma_{f}^{2}}$

where $\sigma_{s f}$ is the conditional covariance of the spot and futures price on information available at prior period $t$-1; i.e., $\sigma_{s f}=\operatorname{Cov}\left(S_{t}, F_{t} \mid I_{t-1}\right)$. Likewise, $\sigma_{f}^{2}$ is the conditional variance of the futures price at $t$ on information available at prior period $t-1$; i.e., $\sigma_{f}^{2}=\operatorname{Var}\left(F_{t} \mid I_{t-1}\right)$. Here $b_{t-1}$ represents a futures short (sell) position and $q_{t-1}$ a cash position at period $t-1$, prior to period $t$ where utility maximization occurs. ${ }^{2}$

A feedlot operation requires corn, soybean meal and feeder cattle as input to 'fatten' the calf, resulting in fed cattle as output for slaughter. For simplicity, veterinary costs, transportation costs and other costs are left constant. Thus the feedlot margin considered is the difference between the sale price of slaughter cattle and the purchasing price of corn, soybean meal and feeder cattle. The feedlot operator's margin is established in line with a previous study by Noussinov and Leuthold (1999). It is assumed that 700-pound steers are purchased by the feedlot operator and fed with 42 bushels of corn and 100 pounds of soybean meal during four months (about 18

${ }^{2}$ Brorsen et al. (1998) arrive similarly at the optimal futures and spot ratio being: $\frac{x_{f}}{-x_{s}}$, estimated as the slope coefficient between futures and spot price changes. A long (buy) futures position here is positive. 
weeks), for an approximate gain of 3.2 pounds a day. This results in a final weight of about 1,100 pounds before sale for slaughter. ${ }^{3}$

Three stages are considered for a total of 22 periods or weeks. The first stage involves production planning where four weeks of planning are considered (i.e., previous to the actual purchase of inputs). Hence futures hedges include concurrently going long in $\operatorname{corn}^{4}\left(\mathrm{~F}_{\mathrm{c}, \mathrm{t}-22}\right)$, soybean meal $\left(\mathrm{F}_{\mathrm{m}, \mathrm{t}-22}\right)$ and feeder cattle $\left(\mathrm{F}_{\mathrm{fc}, \mathrm{t}-22}\right)$ and going short in fed cattle or live cattle $\left(\mathrm{F}_{\mathrm{lc}, \mathrm{t}-}\right.$ 22). The second stage, at the fifth week, begins the operation by purchasing the corn, soybean meal and feeder cattle in the cash market $\left(\mathrm{S}_{\mathrm{c}, \mathrm{t}-18}, \mathrm{~S}_{\mathrm{m}, \mathrm{t}-18,}, \mathrm{~S}_{\mathrm{fc}, \mathrm{t}-18}\right.$, respectively) and concurrently placing a short $\left(\mathrm{F}_{\mathrm{c}, \mathrm{t}-18}, \mathrm{~F}_{\mathrm{m}, \mathrm{t}-18}, \mathrm{~F}_{\mathrm{fc}, \mathrm{t}-18}\right.$, respectively) in the futures market for these inputs, thus liquidating these previous long positions. Subsequently, after 18 weeks of a 'fattening' period, the producer sells the fed cattle $\left(\mathrm{S}_{\mathrm{lc}, \mathrm{t}}\right)$ in the cash market and places a long in the futures markets for this output $\left(\mathrm{F}_{\mathrm{lc}, \mathrm{t}}\right)$, liquidating its previous position.

Thus the hedged feedlot operator's returns or margin for the three previous stages is:

$$
\begin{gathered}
\mathrm{R}_{\mathrm{t}}=\mathrm{S}_{\mathrm{LC}, \mathrm{t}}-\left(\mathrm{S}_{\mathrm{C}, \mathrm{t}-18}+\mathrm{S}_{\mathrm{M}, \mathrm{t}-18}+\mathrm{S}_{\mathrm{FC}, \mathrm{t}-18}\right)+\mathrm{b}_{\mathrm{C}, \mathrm{t}-22}\left(\mathrm{~F}_{\mathrm{C}, \mathrm{t}-18}-\mathrm{F}_{\mathrm{C}, \mathrm{t}-22}\right)+\mathrm{b}_{\mathrm{M}, \mathrm{t}-22}\left(\mathrm{~F}_{\mathrm{M}, \mathrm{t}-18}-\mathrm{F}_{\mathrm{M}, \mathrm{t}-22}\right)+ \\
\mathrm{b}_{\mathrm{FC}, \mathrm{t}-22}\left(\mathrm{~F}_{\mathrm{FC}, \mathrm{t}-18}-\mathrm{F}_{\mathrm{FC}, \mathrm{t}-22}\right)-\mathrm{b}_{\mathrm{LC}, \mathrm{t}-22}\left(\mathrm{~F}_{\mathrm{LC}, \mathrm{t}}-\mathrm{F}_{\mathrm{LC}, \mathrm{t}-22}\right)-\mathrm{c}
\end{gathered}
$$

where $b_{c}, b_{m}, b_{f c}$ and $b_{l c}$ are respectively corn, soybean meal, feeder cattle and fed or live cattle futures contracts on a per fed cattle basis (i.e., 1100 pounds) at the first time period $\mathrm{t}-22$, and $\mathrm{c}$ is an operation cost assumed constant for simplicity. The optimal number of 'pounds of fed cattle' futures contracts determines the respective optimal hedge ratios $b_{i}(i \in c, m, f c$ and $l c)$, obtained by minimizing the variation of the returns.

\footnotetext{
${ }^{3}$ This study considers hedging with futures instruments, leaving the alternative of hedging with options and forward cash markets for further study.

${ }^{4}$ Corn is denoted by subscript "c", Soybean meal is denoted by subscript "m", Feeder cattle is denoted by subscript "fc" and Fed or Live cattle is denoted by subscript "lc".
} 
The variance of the returns, conditional on information of the initial period $t$ for selling 'fattened calf' (considering data back to $t-22)$, is: $:^{5}$

$$
\begin{aligned}
\mathrm{V}(\mathrm{R})= & \sum_{i}\left\{V\left(S_{i}\right)+b_{i}^{2} V\left(F_{i}\right)\right\}+\sum_{j} \sum_{k \neq j} \operatorname{Cov}\left(S_{j}, S_{k}\right)-2 \sum_{j} \operatorname{Cov}\left(S_{j}, S_{l c}\right)+ \\
& 2 b_{j} \sum_{j} \operatorname{Cov}\left(F_{j}, S_{l c}\right)+-2 b_{j} \sum_{j} \sum_{k} \operatorname{Cov}\left(F_{j}, S_{k}\right)-2 b_{l c} \operatorname{Cov}\left(F_{l c}, S_{l c}\right)+ \\
& 2 b_{l c} \sum_{j} \operatorname{Cov}\left(F_{l c}, S_{j}\right)+b_{j} b_{k \neq j} \sum_{j} \sum_{k \neq j} \operatorname{Cov}\left(F_{j}, F_{k}\right)-2 b_{j} b_{l c} \sum_{j} \operatorname{Cov}\left(F_{j}, F_{l c}\right)
\end{aligned}
$$

with $i \in c, m, f c, l c$; and $j, k \in c, m, f c$;

Optimal minimum variance hedge ratios are obtained by partially differentiating the variance with respect to $b_{i}(i \in c, m, f c$ and $l c)$ and equating each differentiated expression to zero. Subsequently, each corresponding equation is solved by applying Cramer's rule (see Appendix 1). Each of these multiproduct time-varying hedge ratios, as well as single time-varying hedge ratios, is computed from the estimated simultaneous time-varying variances and covariances.

The conditional mean and covariance of market prices need to be defined in order to estimate the conditional, time-varying covariance matrix. Following Garcia et al. (1995), the conditional mean of market prices at period $t$ are the expected futures and expected spot prices of each commodity with information from (initial) period $t$-22. For corn, soybean meal and feeder cattle, the spot and future prices at time $t$ considers the timing between planning $(t-22)$ and the beginning of the operation period $(t-18)$. This result in the following conditional 'returns' for corn, soybean meal and feeder cattle at period $t$ with information from period $t-22$ :

$$
\begin{aligned}
& R_{x, t} \mid I_{t-22}=10 *\left[\ln \left(P_{x, t-18}\right)-\ln \left(P_{x, t-22}\right)\right] \quad \text { or } \\
& \left.R_{x, t}=10 *\left[\ln \left(P_{x, t-18}\right)-\ln P_{x, t-22}\right)\right]+u_{p, x, t}
\end{aligned}
$$

\footnotetext{
${ }^{5}$ The time scripts are omitted for simplicity.
} 
where $x$ is either corn $(c)$, soybean meal $(m)$ or feeder cattle $(f c)$, and $P$ are either spot or futures prices.

Likewise for live cattle, the spot and future prices consider the timing between planning $(t-22)$ and selling $(t)$, resulting in the following conditional 'returns':

$$
\begin{aligned}
& R_{l c, t} \mid I_{t-22}=10 *\left[\ln \left(P_{l c, t}\right)-\ln \left(P_{l c, t-22}\right)\right] \\
& R_{l c, t}=10 *\left[\ln \left(P_{l c, t}\right)-\ln \left(P_{l c, t-22}\right)\right]+u_{p, l c, t}
\end{aligned}
$$

where $P$ are either spot or futures prices.

The prediction errors between the actual and expected prices (6) and (7) are identified as the time-varying covariance matrix:

$$
H_{t}=E\left(\varepsilon_{t} \varepsilon_{t}^{\prime} \mid I_{t-22}\right)
$$

where $\varepsilon_{t}=\left(u_{s, c, t}, u_{f, c, t}, u_{s, m, t}, u_{f, m, t}, u_{s, f c, t}, u_{f, f c, t}, u_{s, l c, t}, u_{f, l c, t}\right)$

\section{Econometric Model}

The Regime Switching Dynamic Correlations (RSDC) model considers a $K$ - multivariate time process:

$$
Y_{t}=H_{t}^{1 / 2} U_{t}
$$

where $U_{t} \sim$ i.i.d. $\left(0, I_{K}\right.$ : identity matrix), $Y_{t}$ are the previous price 'returns' from (5) and (6).

The estimated time-varying covariance matrix $H_{t}$ is decomposed into standard deviations and correlations. The series switch between different correlations regimes according to a Markov chain.

$$
H_{t} \equiv S_{t} \Gamma_{t} S_{t}
$$

with $S_{t}$ being a diagonal matrix with standard deviations: $s_{k, t} ; k=1 \ldots . K$ and $\Gamma_{t}$ is the correlations matrix. 
Standard deviations $S_{k, t}$ for each time series $k$ - from diagonal matrix $S_{t}$ - are assumed to follow an ARMACH(1,1) model (Taylor, 1986):

$s_{t}=\omega+\tilde{\alpha}\left|y_{t-1}\right|+\beta s_{t-1} \quad$ with $\tilde{\alpha}=\alpha / E\left|\tilde{u}_{t}\right|$, for stationary purposes.

The time-varying correlation matrix $\Gamma_{t}$ is governed by a Markov chain, having different correlations at different regimes and denotes the parsimonious model from Pelletier (2006):

$\Gamma_{t}=\Gamma \lambda\left(\Delta_{t}\right)+I_{K}\left(1-\lambda\left(\Delta_{t}\right)\right)$

where $\Gamma$ is a fixed $K x K$ correlation matrix. $I_{K}$ is a $K x K$ identity matrix, and $\lambda\left(\Delta_{t}\right) \epsilon[0,1]$ (assuring no possibilities of a non-PSD correlation matrix) is a univariate random process governed by an unobserved Markov chain process $\Delta_{t}$ that takes $N$ possible number of regimes $\left(\Delta_{t}=1,2 \ldots N\right)$, and is independent of $U_{t}$. The 'probability law' governing the Markov chain process $\Delta_{t}$ is defined by its constant transition probability matrix $\Pi_{t}$, with elements of row $i$ and column $j: \pi_{t}^{i, j}$, equivalent to the probability of going from regime $i$ in period $t$ - 1 to regime $j$ in period $t$. Thus switching between regimes becomes an endogenous process.

Two different regimes are assumed for this process. Hence, the correlation matrix at time $t$ $\left(\Gamma_{t}\right)$ is a weighted average of two extreme states - uncorrelated returns by $\lambda\left(\Delta_{t}\right)=0$, or (highly) correlated returns at $\lambda\left(\Delta_{t}\right)=1$. For certain $t$ periods, the time series may be at one regime with a specific set of (higher) correlations, and for other $t$ periods it may be at another regime, with a different set of (lower) correlations. Changes among correlations from one regime to another are proportional by $\lambda\left(\Delta_{t}\right)$.

\section{Estimation:}

For equations (9) and (10), the log-likelihood can be written as: 


$$
\begin{aligned}
L & =-\frac{1}{2} \sum_{t=1}^{T}\left[K \log (2 \pi)+\log \left(\left|H_{t}\right|\right)+Y_{t}^{\prime} H_{t}^{-1} Y_{t}\right] \\
& =-\frac{1}{2} \sum_{t=1}^{T}\left[K \log (2 \pi)+\log \left(\left|S_{t} \Gamma_{t} S_{t}\right|\right)+Y_{t}^{\prime} S_{t}^{-1} \Gamma_{t}^{-1} S_{t}^{-1} Y_{t}\right] \\
L & =-\frac{1}{2} \sum_{t=1}^{T}\left[K \log (2 \pi)+2 \log \left(\left|S_{t}\right|\right)+\log \left(\left|\Gamma_{t}\right|\right)+\widetilde{U}_{t}^{\prime} \Gamma_{t}^{-1} \widetilde{U}_{t}\right]
\end{aligned}
$$

where $\widetilde{U}_{t}=S_{t}^{-1} Y_{t}$ and $\widetilde{U}_{t}=\left[\tilde{u}_{1, t} \ldots \ldots \ldots \ldots \tilde{u}_{K, t}\right]^{\prime}$ is a zero mean process with covariance matrix $\Gamma_{t}$; and $\left|H_{t}\right|=\operatorname{det}\left(H_{t}\right)$.

Estimation of model parameters is made in two separate steps. Standard deviations are estimated first and subsequently the correlations are estimated, both via maximum likelihood, and using a correlation targeting method to determine lambda and correlation parameters. ${ }^{6}$ Estimation results are generated using Ox version 5.0 (Doornik, 2007).

\section{Data}

Weekly spot and futures prices are used for corn, soybean meal, feeder cattle and live cattle taken each Wednesday, and if missing, that week's Tuesday or Thursday value is considered. All prices were converted to dollars on a "per fed cattle basis". The corn cash prices are quotes from the Central Illinois elevator and the soybean meal cash prices are bid quotes from Decatur, Illinois. These prices were obtained from AMS - USDA. Cash prices for feeder cattle are from Oklahoma City and for fed cattle are from the average of Texas-Oklahoma, both obtained from the CRB database. The futures quotes for corn and soybean meal are closing prices at the Chicago Board of Trade (CBOT), and futures prices for feeder cattle and live cattle are from Chicago Mercantile Exchange (CME). All futures prices are likewise obtained from CRB

\footnotetext{
${ }^{6}$ Further estimation details in Pelletier (2006).
} 
database. Nearest to expiration futures contracts were used, leaving out data from the expiring delivery month. The in-sample data spans from the first week of December in 1998 until the first week in October 2008, consisting of 513 observations. The out-of-sample data consists of weekly prices from the second week of October 2008 till the third week of March 2012, for 181 observations. A chart of the in-sample cash and futures prices - on dollars per fed cattle basis are in Figure 1and for out-of-sample data in Figure 2.

(Insert Figures 1 and 2 about here)

\section{Results}

Tables 1 and 2 present estimated correlations between cash and future prices of corn, soybean meal, feeder cattle and live cattle, for the two regimes considered.

(Insert Tables 1 and 2 about here)

At each particular regime, the correlation between the cash and futures prices of each commodity is statistically significant. Moreover, the cash and futures price correlation for corn, soybean meal and live cattle is significantly different from one regime with respect to the other. Thus there is a (significantly) different correlation for the spot and futures prices of corn, soybean meal and live cattle between each regime. These different correlations range from 0.918 at regime 1 to about 0.652 at regime 2 for corn, from 0.972 to 0.690 for soybean meal, and from 0.639 to about 0.454 for live cattle, respectively. Figure 3 shows the dynamic correlations between live cattle cash prices and live cattle futures at each estimated regime. ${ }^{7}$

\footnotetext{
${ }^{7}$ A separate study examines (weakly) exogenous factors that affect the changes between regimes by applying an extended model (Tejeda et al., 2009), to gauge the impact of underlying fundamentals in the dynamic process.
} 
In addition, correlations between prices of different commodities are likewise significantly different. E.g., correlations for corn spot prices and soybean meal futures range from 0.509 for regime 1 to 0.361 for regime 2; and for feeder cattle futures and live cattle futures range from 0.296 to 0.210 at regimes 1 and 2 , respectively.

(Insert Figure 3 about here)

The ARMACH model results for each price are in Table 3. In general, the ARMACH parameters are significant for all price series, excepting the conditional volatility which is not (significantly) dependent upon the previous volatility level.

(Insert Table 3 about here)

The optimal dynamic hedge ratios - for in sample data - of feeder cattle are in Figures 4 and 5. Specifically, these figures present optimal dynamic corn hedge ratios, at the two regimes, for multiproduct time-varying hedge and single time-varying hedge, respectively. In addition, there is a dynamic 'minimum-variance-combination' (MVC) hedge ratio, which picks the timevarying hedge ratio - among the two regimes - that delivers the minimum margin variance at that particular date.

(Insert Figures 4 and 5 about here)

The average of these optimal dynamic hedge ratios for corn, soybean meal, feeder cattle and live cattle - using in-sample data - are in Table 4. From this Table 4, the average optimal multiproduct dynamic hedge ratio in regime 2 for corn and feeder cattle is significantly higher and lower, respectively, than that of single time-varying correlations in regime 2. E.g. for corn it is 0.413 over 0.281 ; and for feeder cattle it is 0.110 below 0.252 , respectively. This may also be (somewhat) inferred from the charts in Figures 4 and 5. In addition, the average MVC hedge ratio for corn and feeder cattle is significantly higher and lower, respectively, in the multiproduct 
time-varying operation over the single commodity time-varying operation (i.e. 0.417 above 0.336 for corn, and 0.227 below 0.302 for feeder cattle). Moreover, these MVC hedge ratios are significantly lower than one - the naive hedge ratio. Improvements obtained from the timevarying hedge ratios suggest that take into account the dynamic variability of the correlation among related prices, substantially lowers the optimal hedge ratios. Thus identifying the effects of changing market conditions on related markets enables to depict superior hedge ratios and risk management tools.

(Insert Table 4 about here)

The out-of-sample data results for optimal dynamic hedge ratios of feeder cattle are in Figures 6 and 7. These include the MVC hedge ratio which 'picks' the hedge ratio, between the two regimes, that minimizes the margin variance. Table 5 presents the average of these optimal dynamic hedge ratios. Once again, in regime 2 the average optimal hedge ratios for corn and feeder cattle are significantly higher and lower, respectively, for multiproduct time-varying correlations over single time-varying correlations. E.g. for corn it is 0.436 over 0.317 , and for feeder cattle it is 0.216 below 0.325 . The differences in feeder cattle can be observed in Figures 6 and 7.

(Insert Figures 6 and 7 about here)

In addition, the average MVC hedge ratio is likewise higher for corn and lower for feeder cattle, upon considering multiproduct time-varying correlations over single time-varying correlations. These MVC hedge ratios are somewhat similar to the in-sample data. These results corroborate those from in-sample data.

(Insert Table 5 about here) 
The hedging effectiveness results for in sample data are presented in Table 6. Here the variance of the margin without hedge is compared to the variance of the margin applying either a naive (1:1) hedge, or single commodity time-varying hedge ratios for each regime and the MVC of these two regimes. Likewise, it is compared with the multiproduct time-varying hedge ratios considering each regime and the MVC of the two regimes. The naive hedge provides an immediate variance reduction of about $12 \%$ over the un-hedged operation. This variance reduction is surpassed by each of the two regimes, considering either single or multiproduct time-varying correlations, with values between $24.5 \%$, and $23.6 \%$; respectively. However, application of the MVC for either single or multiproduct time-varying correlations results in the largest margin variance reduction. In particular, applying the MVC for the multiproduct timevarying correlations case results in a substantial margin variance reduction of $34.8 \%$, and similarly in a $34.9 \%$ variance reduction for the single commodity time-varying hedge ratio. This is a substantial increase in reduction of margin variance by more than double-fold in comparison to the naive hedging strategy. These substantial improvements are a direct result of taking into account the dynamic (changing) conditions of the markets, given that relative changes in market conditions have different effects on each associated commodity.

\section{(Insert Table 6 about here)}

The out of sample hedging effectiveness is presented in Table 7. The margin variance reduction for naive hedging is about $42 \%$. This reduction is once again below that of the application of optimal hedge ratios, at each particular regime, from single or multiproduct timevarying correlations. These latter hedging strategies result in a margin variance reduction of between $50 \%$ and $45 \%$ (regimes 1 and 2 ) and 52\% and $46 \%$ (regimes 1 and 2), for single or multiproduct time-varying correlations, respectively. However, the MVC hedge ratios in both 
single and multiproduct time-varying correlations deliver once again a larger drop in margin variance with $57.3 \%$ and $59.8 \%$ respectively. The MVC hedge ratio for single commodity is about $15 \%$ points larger than the naive strategy, and the MVC from multiproduct time-varying hedge ratios obtains an increase in margin reduction variance of about $41 \%$ (17.3\% points) in comparison to the naive hedging strategy. Thus there is considerable improvement by applying the MVC of multiproduct optimal hedge ratios over the naive hedging strategy, for out-of-sample data for the feedlot operation considered.

\section{(Insert Table 7 about here)}

These findings are obtained by applying two improvements from the prior study regarding multiproduct optimal time-varying hedging strategy of a cattle feedlot operation. First, the timeseries is a weekly process (instead of average monthly data) estimated with a time-varying correlations model that specifically characterizes the significant changes in correlations among the prices, along the time-series. Second is the extensive period of data for parameter estimation, with an in-sample set of weekly prices of about 10 years and out-of-sample data covering more than three years. Thus consistent with findings of Haigh and Holt (2000), ${ }^{8}$ considering the timevarying estimation of multiproduct covariances (correlations) in a multi-product (related) setting, results in improvements over the case of naive hedging. Moreover, Noussinov and Leuthold (1999) study likewise arrived at a significantly lower optimal average feeder cattle hedge ratio. However, without estimating/applying simultaneous time-varying correlations, they reached mixed results for margin variance reduction over a naive hedging strategy.

\section{Conclusion}

\footnotetext{
${ }^{8}$ This study likewise uses weekly data, for an in-sample period of over 11 years.
} 
This article examines the application of estimated time-varying correlations to an optimal multiproduct hedge setting, specifically a cattle feedlot operation. The multiproduct time-varying hedge ratios are obtained by applying a regime switching dynamic correlations (RSDC) model (Pelletier, 2006) which estimates dynamic correlations that switch between two different levels or regimes. These time-varying correlations better characterize the dynamic relationships among prices than if estimated with a constant correlations model, since the model identifies significant price correlations at two different regimes, with the switch between regimes being governed by a first order Markov chain.

Findings of the study are three-fold. First, there is a significant correlation among each pair of commodity (spot and future) prices, as well as a significant difference between correlations of commodities in the operation from one regime to another. This latter occurs for spot and future prices of corn, soybean meal and live cattle (e.g. corn spot and future prices have two significant different dynamic correlations, same for soybean meal and live cattle), and more importantly, for some prices between two different commodities (e.g. corn spot prices and soybean meal future prices have two significantly different dynamic correlations).

Second, there is an improvement in the reduction of margin variance by applying timevarying optimal hedge ratios with both multiproduct (RSDC) and single commodity settings, but more importantly, over the naive hedging strategy. This improvement is considerable for insample data, by more than double-fold margin variance reduction over naive (1:1) hedging; though this difference moderates for out-of-sample data with about a $41 \%$ improvement in margin variance reduction over naive (1:1) hedging. This advance is obtained by applying a minimum-variance-combination (MVC) of the optimal dynamic hedge ratios estimated from each regime. 
Third, optimal average multiproduct hedge ratios are significantly below one, especially the MVC hedge ratios with corn at 0.46 , feeder cattle at 0.36 and live cattle at 0.62 considering the multiproduct optimal hedging strategy. Similar values are obtained with the single commodity hedging strategy. These result in lower hedging costs for the agent as a full hedge is unwarranted.

A limitation of the framework implemented is that once the hedge is set, it is not possible to modify or update the hedge position in the next period. This is something that may be introduced in future work.

\section{References:}

Alizadeh, A. and Nomikos, N. (2004). A Markov regime switching approach for hedging stock indices. The Journal of Futures Markets, 24, 649 - 674

Anderson, R. and Danthine, J.P. (1980). Hedging and Joint Production: Theory and Illustration. Journal of Finance, 35, $487-498$.

Baillie, R.T. and Myers, R.J.. (1991). Bivariate GARCH estimation of the Optimal Commodity Futures Hedge. Journal of Applied Econometrics, 6, 109-124.

Bekkerman. A. (2011). Time-Varying Hedge Ratios in Linked Agricultural Markets; Agricultural Finance Review, 71 (2), 179-200.

Benninga, S., Eldor, R., and Zilcha, I. (1984). The Optimal Hedge Ratio in Unbiased Futures Markets. The Journal of Futures Markets, 4, 155-159

Bera, A., Garcia, P., and Roh, J. (1997). Estimation of Time-Varying Hedge Ratio for Corn and Soybean: BGARCH and Random Coefficient Approaches. The Indian Journal of Statistics, 59, 346-368 
Bollerslev, T., Engle, R., and Wooldridge, J. (1998). A capital asset pricing model with timevarying covariances. Journal of Political Economy, 96, 116-131

Bollerslev, T., (1998). On the correlation structure for the generalized autoregressive conditional heteroscedastic process. Journal of Time Series Analysis, 9, 121-131

Bollerslev, T. (1990). Modelling the coherence in short-run nominal exchange rates: A multivariate generalized ARCH model. Review of Economics and Statistics, 52, 5-59.

Brorsen, B.W., Buck, D.W., and Koontz, S.R. (1998). Hedging Hard Red Winter Wheat: Kansas City versus Chicago. The Journal of Futures Markets, 18, 449-466

Choudhry. T. (2004). The hedging effectiveness of constant $\&$ time-varying hedge ratios using three Pacific Basin stock futures; International Review of Economics \& Finance,13,371-5

Choudhry. T. (2009). Short-run Deviations and Time-Varying Hedge Ratios: Evidence from Agricultural Futures Markets; International Review of Financial Analysis, 18, 58-65

Collins, R.A. (2000). The risk management effectiveness of multivariate hedging models in the U.S. Soy Complex. The Journal of Futures Markets, 20, 189-204

Doornik, J.A. (2007). Object-Oriented Matrix Programming Using Ox, $3^{\text {rd }}$ ed. London: Timberlake Consultants Press and Oxford: www.doornik.com

Engle, R. F. and Kroner, K.F. (1995). Multivariate Simultaneous Generalized ARCH. Econometric Theory 11:122-150.

Engle, R. (2002). Dynamic conditional correlation: A simple class of multivariate generalized autoregressive conditional heteroskedasticity models. Journal of Business \& Economic Statistics, 20, 339-350.

Fackler, P.L. and McNew, K.P. (1993). Multiproduct hedging: Theory, estimation, and an application. Review of Agricultural Economics, 15, 521-535. 
Garcia, P., Roh, J. and Leuthold, R.M.. (1995). Simultaneously Determined, Time Varying Hedge Ratios in the Soy Complex. Applied Economics, 27, 1127-1134

Haigh, M.S. and Holt, M.T. (2000). Hedging multiple price uncertainty in international grain trade. American Journal of Agricultural Economics, 82, 881-896

Hammoudeh, S., Yuan, Y., McAleer, M., and Thompson, M.A. (2010). Precious-metals exchange rate volatility transmission and hedging strategies. International Review of Economics and Finance, 19, 633-647

Ji, Q. and Fan, Y. (2011). A dynamic hedging approach for refineries in multiproduct oil markets. Energy 36, 881-887

Johnson, L.L. (1960). The Theory of Hedging and Speculation in Commodity Futures. Review of Economic Studies, 27, 139-151

Lee, T. (1994). Spread and Volatility in Spot and Forward Exchange Rates. Journal of International Money and Finance, 13, 375-383.

Lien, D. and Tse, Y.K. (2002). Some Recent Developments in Futures Hedging. Journal of Economics Surveys, 16(3), 357-396

Leuthold, R.M., Junkus, J.C. and Cordier, J.E. (1989). The Theory and Practice of Futures Markets. Lexington MA: Lexington Books.

Manfredo, M.R., Garcia, P. and Leuthold, R.M. (2000). Time-Varying Multiproduct Hedge Ratio estimation in the Soybean Complex: A Simplified Approach. Paper presented at the NCR-134 Conference on Applied Commodity Price Analysis, Forecasting, and Market Risk Management. Chicago, Illinois, April 17-18, 2000.

Myers, R.J., and Thompson, S.R. (1989). Generalized Optimal Hedge Ratio Estimation. American Journal of Agricultural Economics, 71, 858-868. 
Noussinov, M.A., and Leuthold, R.M. (1999). Optimal hedging strategies for the U.S. cattle feeder. Journal of Agribusiness, 17, 1-19

Park, S. Y., and Jei, S.Y. (2010). Estimation and Hedging Effectiveness of Time-Varying Hedge Ratio: Flexible Bivariate GARCH Approaches. The Journal of Futures Markets 30: 71-99

Pelletier, D. (2006). Regime Switching for Dynamic Correlations. Journal of Econometrics, 131:445-473.

Peterson, P. and Leuthold, R. (1987). A Portfolio approach to Optimal Hedging for a Commercial Feedlot. The Journal of Futures Markets, 7, 443-457.

Sephton, P. (1993). Optimal Hedge Ratios at the Winnipeg Commodity Exchange. Canadian Journal of Economics, 26(1):175-193.

Taylor, S. (1986). Modelling Financial Time Series. Wiley, New York.

Tejeda, H.A., Goodwin, B.K. and Pelletier D. (2009). A State Dependent Regime Switching Model of Dynamic Correlations, Selected paper presented at the AAEA Annual meeting, Milwaukee, WI., July 26-28, 2009.

Tzang, D., and Leuthold, R. (1990). Hedge ratios under inherent risk reduction in a commodity complex. The Journal of Futures Markets, 10, 497-504.

Zanotti, G., Gabbi, G., and Geranio, M (2010). Hedging with Futures: Efficacy of GARCH correlation models to European electricity markets. Journal of International Financial Markets, Institutions and Money, 20:135-148 


\section{Appendix 1}

Multiproduct Time-Varying Hedge Ratios:

$\mathrm{b}_{c, \mathrm{t}-22}=$
$\begin{array}{cccc}\operatorname{Cov}\left(F_{c}, S_{c}\right)+\operatorname{Cov}\left(F_{c}, S_{m}\right)+\operatorname{Cov}\left(F_{c}, S_{f c}\right)-\operatorname{Cov}\left(F_{c}, S_{l c}\right) & \operatorname{Cov}\left(F_{c}, F_{m}\right) & \operatorname{Cov}\left(F_{c}, F_{f c}\right) & -\operatorname{Cov}\left(F_{c}, F_{l c}\right) \\ \operatorname{Cov}\left(F_{m}, S_{c}\right)+\operatorname{Cov}\left(F_{m}, S_{m}\right)+\operatorname{Cov}\left(F_{m}, S_{f c}\right)-\operatorname{Cov}\left(F_{m}, S_{l c}\right) & \operatorname{Var}\left(F_{m}\right) & \operatorname{Cov}\left(F_{m}, F_{f c}\right) & -\operatorname{Cov}\left(F_{m}, S_{l c}\right) \\ \operatorname{Cov}\left(F_{f c}, S_{m}\right)+\operatorname{Cov}\left(F_{f c}, S_{m}\right)+\operatorname{Cov}\left(F_{f c}, S_{f c}\right)-\operatorname{Cov}\left(F_{f c}, S_{l c}\right) & \operatorname{Cov}\left(F_{f c}, F_{m}\right) & \operatorname{Var}\left(F_{f c}\right) & -\operatorname{Cov}\left(F_{f c}, F_{l c}\right) \\ \operatorname{Cov}\left(F_{l c}, S_{c}\right)+\operatorname{Cov}\left(F_{l c}, S_{m}\right)+\operatorname{Cov}\left(F_{l c}, S_{f c}\right)-\operatorname{Cov}\left(F_{l c}, S_{l c}\right) & \operatorname{Cov}\left(F_{m}, F_{l c}\right) & \operatorname{Cov}\left(F_{f c}, F_{l c}\right) & -\operatorname{Var}\left(F_{l c}\right) \\ \end{array}$

D

$\mathrm{b}_{\mathrm{m}, \mathrm{t}-22}=$

$\left|\begin{array}{lllc|}\operatorname{Var}\left(F_{c}\right) & \operatorname{Cov}\left(F_{c}, S_{c}\right)+\operatorname{Cov}\left(F_{c}, S_{m}\right)+\operatorname{Cov}\left(F_{c}, S_{f c}\right)-\operatorname{Cov}\left(F_{c}, S_{l c}\right) & \operatorname{Cov}\left(F_{c}, F_{f c}\right) & -\operatorname{Cov}\left(F_{c}, F_{l c}\right) \\ \operatorname{Cov}\left(F_{c}, F_{m}\right) & \operatorname{Cov}\left(F_{m}, S_{c}\right)+\operatorname{Cov}\left(F_{m}, S_{m}\right)+\operatorname{Cov}\left(F_{m}, S_{f c}\right)-\operatorname{Cov}\left(F_{m}, S_{l c}\right) & \operatorname{Cov}\left(F_{m}, F_{f c}\right) & -\operatorname{Cov}\left(F_{m}, S_{l c}\right) \\ \operatorname{Cov}\left(F_{c}, F_{f c}\right) & \operatorname{Cov}\left(F_{f c}, S_{m}\right)+\operatorname{Cov}\left(F_{f c}, S_{m}\right)+\operatorname{Cov}\left(F_{f c}, S_{f c}\right)-\operatorname{Cov}\left(F_{f c}, S_{l c}\right) & \operatorname{Var}\left(F_{f c}\right) & -\operatorname{Cov}\left(F_{f c}, F_{l c}\right) \\ \operatorname{Cov}\left(F_{c}, F_{l c}\right) & \operatorname{Cov}\left(F_{l c}, S_{c}\right)+\operatorname{Cov}\left(F_{l c}, S_{m}\right)+\operatorname{Cov}\left(F_{l c}, S_{f c}\right)-\operatorname{Cov}\left(F_{l c}, S_{l c}\right) & \operatorname{Cov}\left(F_{f c}, F_{l c}\right) & -\operatorname{Var}\left(F_{l c}\right)\end{array}\right|$

D

$\mathrm{b}_{\mathrm{fc}, \mathrm{t}-22}=$

$\left|\begin{array}{cccc}\operatorname{Var}\left(F_{c}\right) & \operatorname{Cov}\left(F_{c}, F_{m}\right) & \operatorname{Cov}\left(F_{c}, S_{c}\right)+\operatorname{Cov}\left(F_{c}, S_{m}\right)+\operatorname{Cov}\left(F_{c}, S_{f c}\right)-\operatorname{Cov}\left(F_{c}, S_{l c}\right) & -\operatorname{Cov}\left(F_{c}, F_{l c}\right) \\ \operatorname{Cov}\left(F_{c}, F_{m}\right) & \operatorname{Var}\left(F_{m}\right) & \operatorname{Cov}\left(F_{m}, S_{c}\right)+\operatorname{Cov}\left(F_{m}, S_{m}\right)+\operatorname{Cov}\left(F_{m}, S_{f c}\right)-\operatorname{Cov}\left(F_{m}, S_{l c}\right) & -\operatorname{Cov}\left(F_{m}, S_{l c}\right) \\ \operatorname{Cov}\left(F_{c}, F_{f c}\right) & \operatorname{Cov}\left(F_{f c}, F_{m}\right) & \operatorname{Cov}\left(F_{f c}, S_{m}\right)+\operatorname{Cov}\left(F_{f c}, S_{m}\right)+\operatorname{Cov}\left(F_{f c}, S_{f c}\right)-\operatorname{Cov}\left(F_{f c}, S_{l c}\right) & -\operatorname{Cov}\left(F_{f c}, F_{l c}\right) \\ \operatorname{Cov}\left(F_{c}, F_{l c}\right) & \operatorname{Cov}\left(F_{m}, F_{l c}\right) & \operatorname{Cov}\left(F_{l c}, S_{c}\right)+\operatorname{Cov}\left(F_{l c}, S_{m}\right)+\operatorname{Cov}\left(F_{l c}, S_{f c}\right)-\operatorname{Cov}\left(F_{l c}, S_{l c}\right) & -\operatorname{Var}\left(F_{l c}\right)\end{array}\right|$

D 


\begin{tabular}{|c|c|c|c|}
\hline \multicolumn{4}{|l|}{$\mathrm{b}_{\mathrm{lc}, \mathrm{t}-22}=$} \\
\hline $\operatorname{Var}\left(F_{c}\right)$ & $\operatorname{Cov}\left(F_{c}, F_{m}\right)$ & $\operatorname{Cov}\left(F_{c}, F_{f c}\right)$ & $\operatorname{Cov}\left(F_{c}, S_{c}\right)+\operatorname{Cov}$ \\
\hline $\operatorname{Cov}\left(F_{c}, F_{m}\right)$ & $\operatorname{Var}\left(F_{m}\right)$ & $\operatorname{Cov}\left(F_{m}, F_{f c}\right)$ & $\operatorname{Cov}\left(F_{m}, S_{c}\right)+\operatorname{Cov}($ \\
\hline $\operatorname{Cov}\left(F_{c}, F_{f c}\right)$ & $\operatorname{Cov}\left(F_{f c}, F_{m}\right)$ & $\operatorname{Var}\left(F_{f c}\right)$ & $\operatorname{Cov}\left(F_{f c}, S_{m}\right)+\operatorname{Cov}$ \\
\hline $\operatorname{Cov}\left(F_{c}, F_{l c}\right)$ & $\operatorname{Cov}\left(F_{m}, F_{l c}\right)$ & $\operatorname{Cov}\left(F_{f c}, F_{l c}\right)$ & $\operatorname{Cov}\left(F_{l c}, S_{c}\right)+\operatorname{Cov}$ \\
\hline & & $\mathrm{D}$ & \\
\hline $\mathrm{D}=$ & & & \\
\hline $\operatorname{Var}\left(F_{c}\right)$ & $\operatorname{Cov}\left(F_{c}, F_{m}\right)$ & $\operatorname{Cov}\left(F_{c}, F_{f c}\right)$ & $-\operatorname{Cov}\left(F_{c}, F_{l c}\right)$ \\
\hline $\operatorname{Cov}\left(F_{c}, F_{m}\right)$ & $\operatorname{Var}\left(F_{m}\right)$ & $\operatorname{Cov}\left(F_{m}, F_{f c}\right)$ & $-\operatorname{Cov}\left(F_{m}, S_{l c}\right)$ \\
\hline $\operatorname{Cov}\left(F_{c}, F_{f c}\right)$ & $\operatorname{Cov}\left(F_{f c}, F_{m}\right)$ & $\operatorname{Var}\left(F_{f c}\right)$ & $-\operatorname{Cov}\left(F_{f c}, F_{l c}\right)$ \\
\hline $\operatorname{Cov}\left(F_{c}, F_{l c}\right)$ & $\operatorname{Cov}\left(F_{m}, F_{l c}\right)$ & $\operatorname{Cov}\left(F_{f c}, F_{l c}\right)$ & $-\operatorname{Var}\left(F_{l c}\right)$ \\
\hline
\end{tabular}

\section{Single Time-Varying Hedge Ratios}

$\mathrm{b}_{\mathrm{c}, \mathrm{t}-22}=\frac{\operatorname{Cov}\left(F_{C}, S_{C}\right)}{\operatorname{Var}\left(F_{C}\right)} ;$

$\mathrm{b}_{\mathrm{m}, \mathrm{t}-22}=\frac{\operatorname{Cov}\left(F_{m}, S_{m}\right)}{\operatorname{Var}\left(F_{m}\right)} ;$

$\mathrm{b}_{\mathrm{fc}, \mathrm{t}-22}=\frac{\operatorname{Cov}\left(F_{f c}, S_{f c}\right)}{\operatorname{Var}\left(F_{f c}\right)} ;$

$\mathrm{b}_{\mathrm{lc}, \mathrm{t}-22}=\frac{\operatorname{Cov}\left(F_{l c}, S_{l c}\right)}{\operatorname{Var}\left(F_{l c}\right)} ;$ 


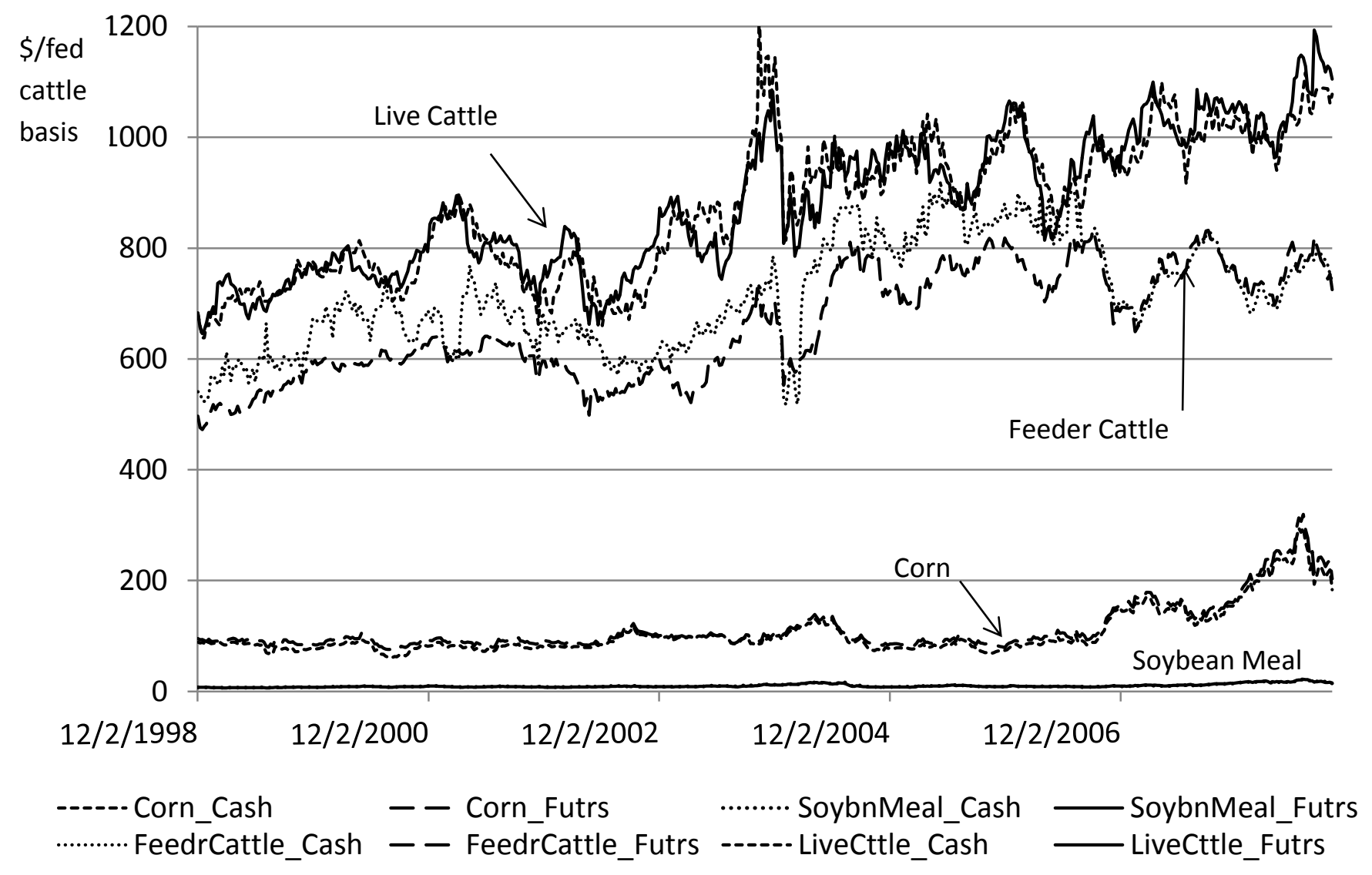

Figure 1: Corn, Soybean Meal, Feeder Cattle and Live Cattle Cash \& Futures Prices

- In Sample Data 


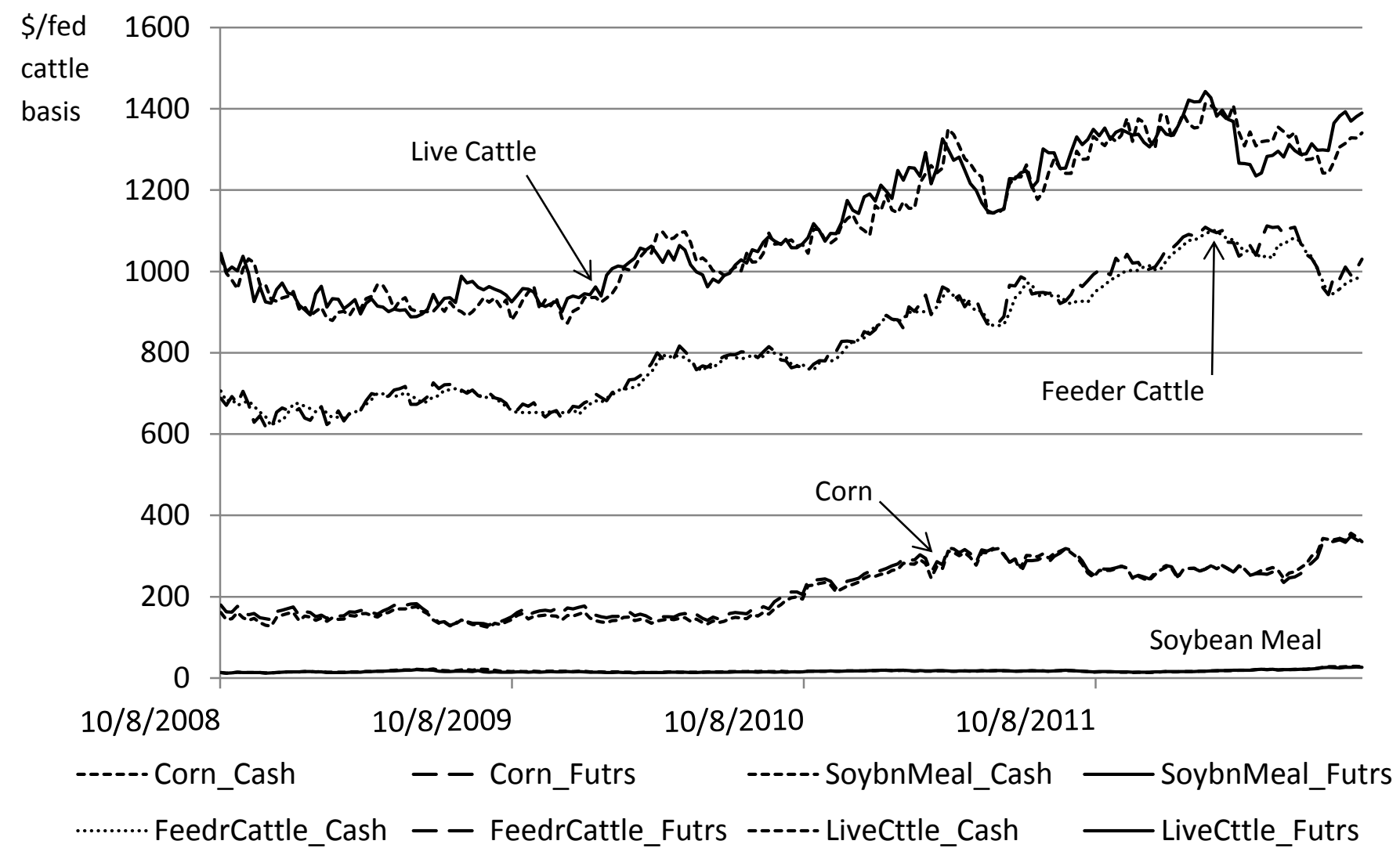

Figure 2: Corn, Soybean Meal, Feeder Cattle and Live Cattle Cash \& Futures Prices

- Out of Sample Data 


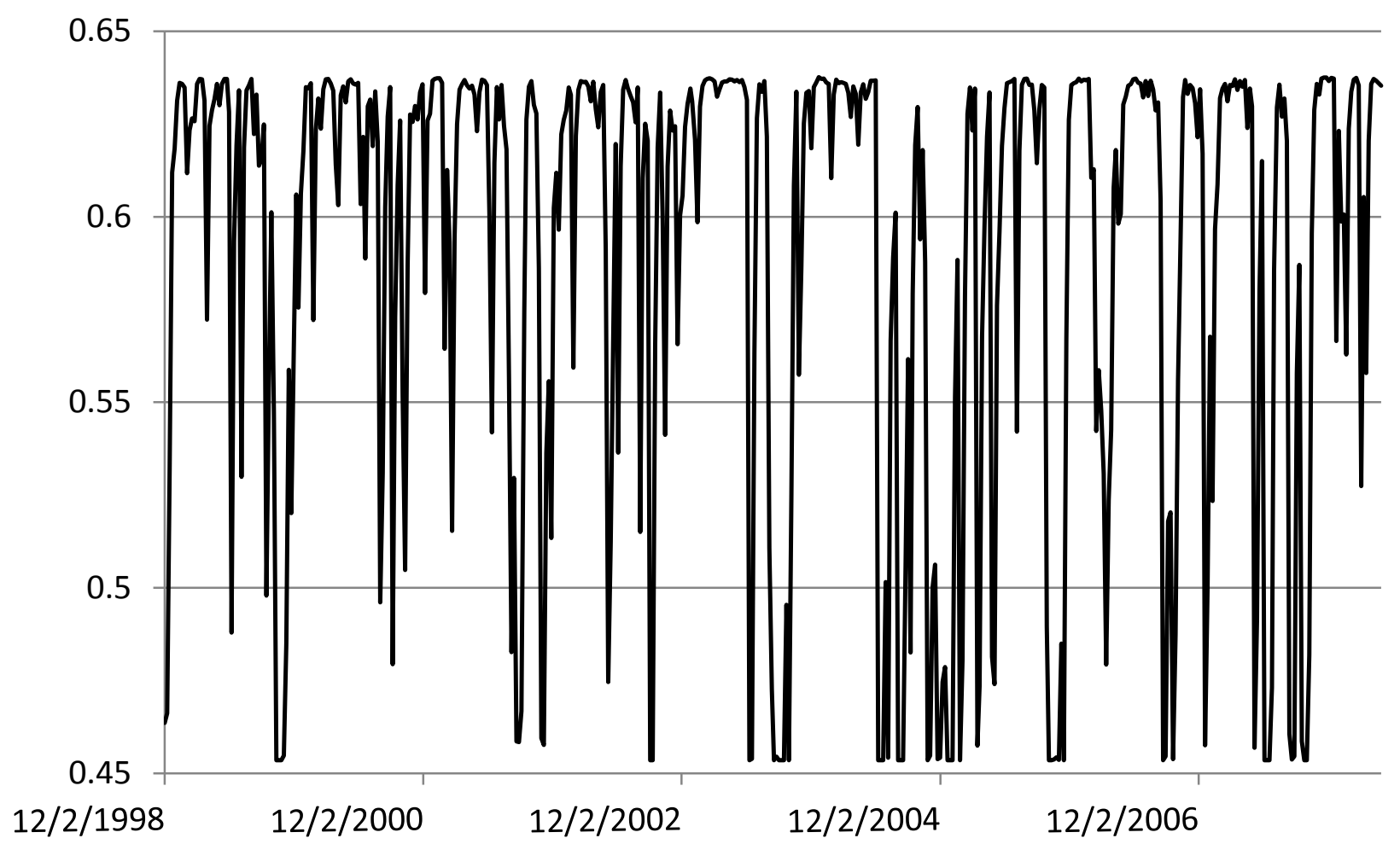

Figure 3: Dynamic Correlation for Live Cattle Cash Prices \& Live Cattle Futures 


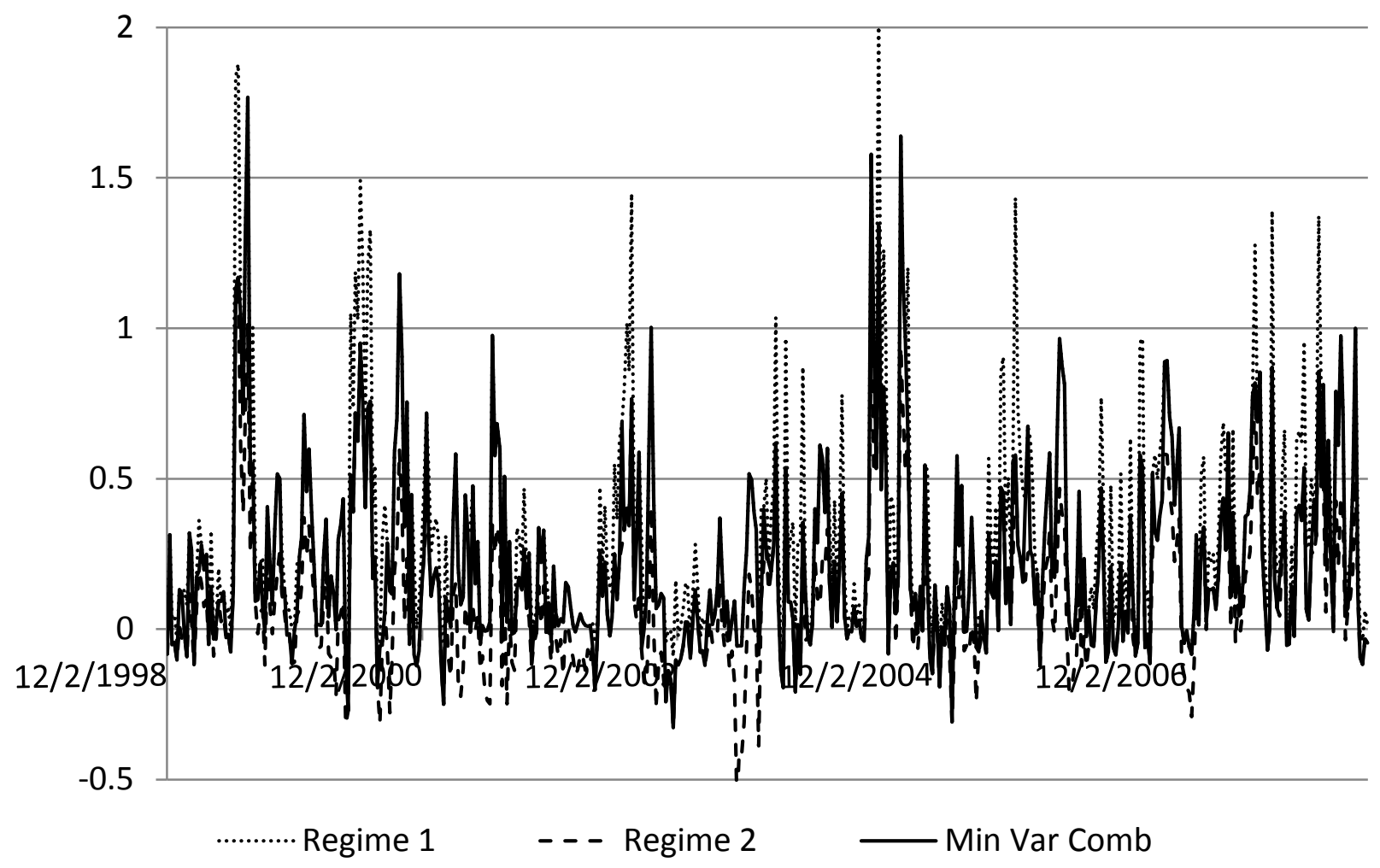

Figure. 4. In-Sample: Dynamic Multiproduct Hedge Ratios - Feeder Cattle Futures 


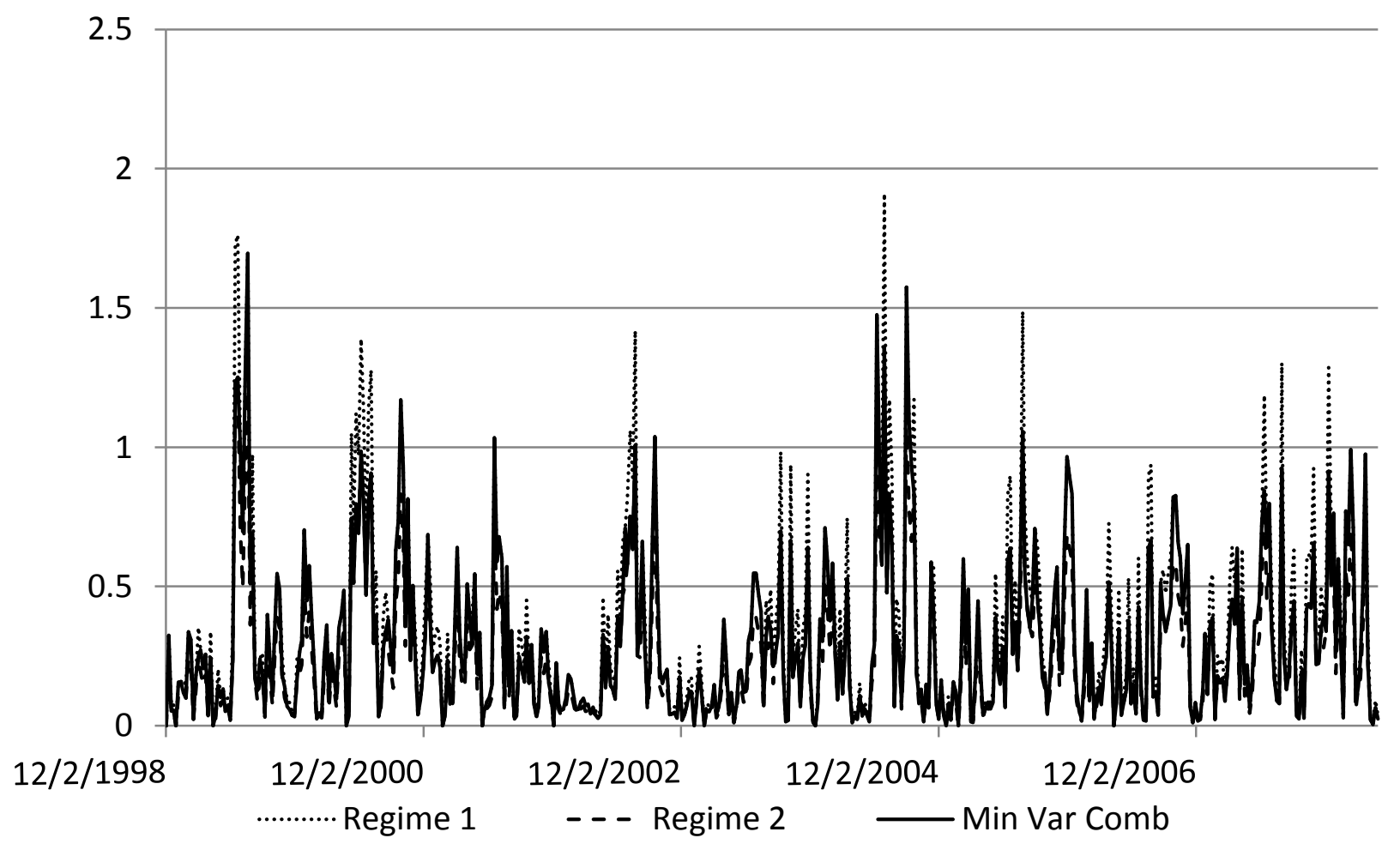

Figure. 5. In-Sample: Dynamic Single Hedge Ratios - Feeder Cattle Futures 


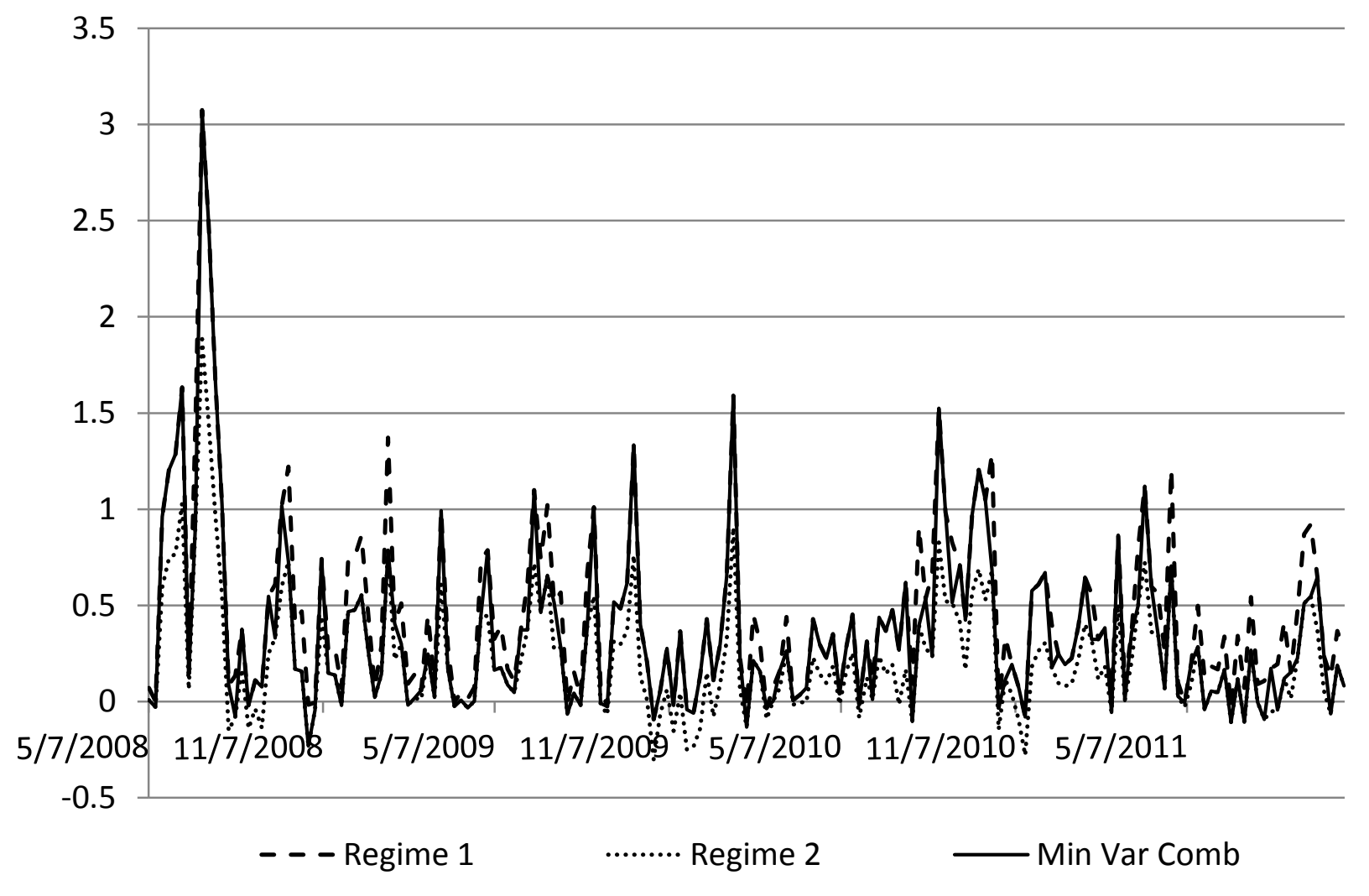

Figure. 6. Out-of-Sample: Dynamic Multiproduct Hedge Ratios - Feeder Cattle Futures 


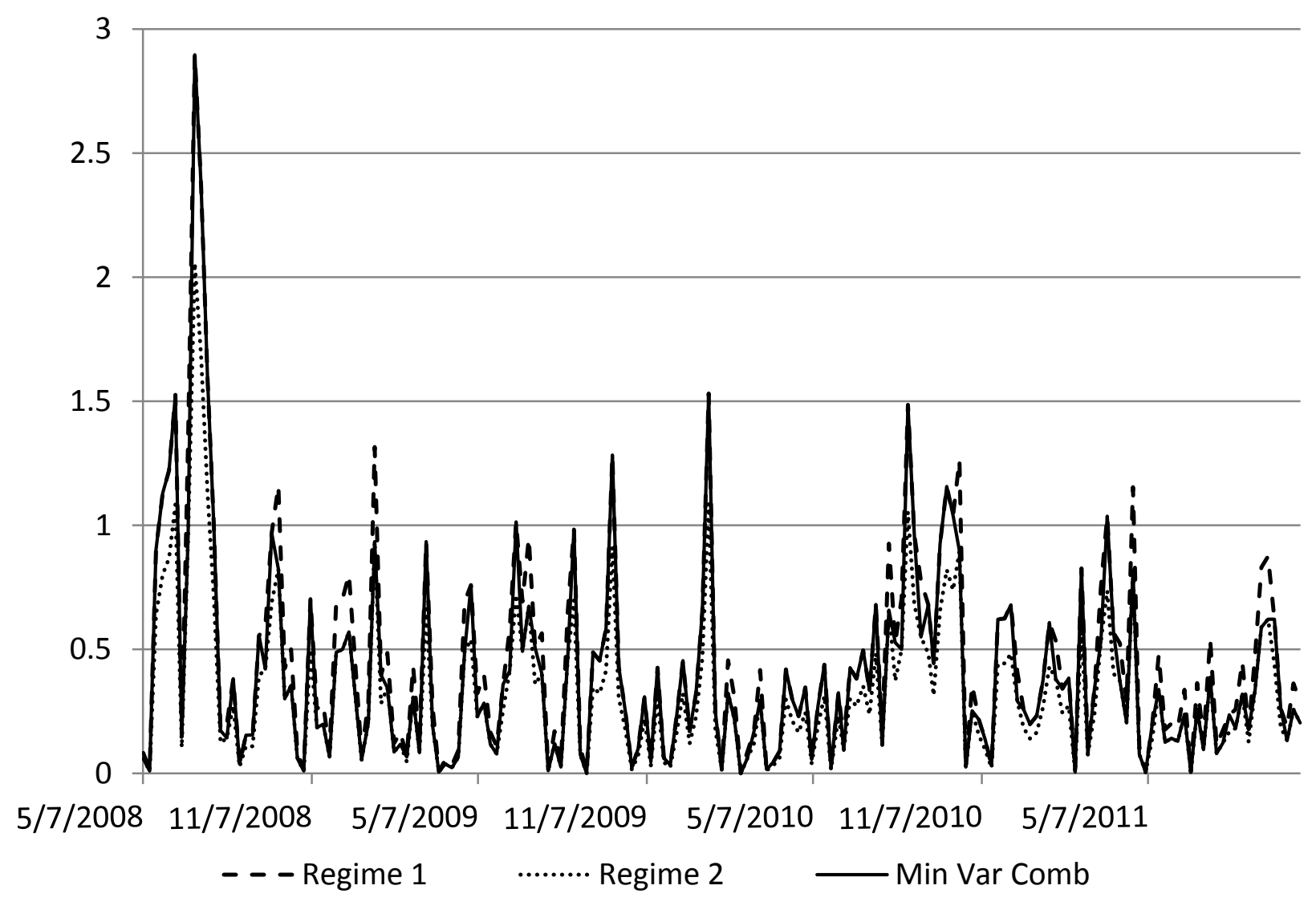

Figure. 7. Out-of-Sample: Dynamic Single Hedge Ratios - Feeder Cattle Futures 


\section{Table 1 Regime 1 - Correlation Values ${ }^{2}$ for Feedlot Operation}

\begin{tabular}{|c|c|c|c|c|c|c|c|c|}
\hline Regime 1 & Corn Cash & $\begin{array}{l}\text { Soybean Meal } \\
\text { Cash }\end{array}$ & $\begin{array}{l}\text { Feeder } \\
\text { Cattle Cash }\end{array}$ & $\begin{array}{l}\text { Live } \\
\text { Cattle } \\
\text { Cash }\end{array}$ & $\begin{array}{l}\text { Corn } \\
\text { Futures }\end{array}$ & $\begin{array}{l}\text { Soybean } \\
\text { Meal } \\
\text { Futures }\end{array}$ & $\begin{array}{l}\text { Feeder Cattle } \\
\text { Futures }\end{array}$ & $\begin{array}{l}\text { Live Cattle } \\
\text { Futures }\end{array}$ \\
\hline Corn Cash & 1.0000 & & & & & & & \\
\hline Soybean Meal Cash & $\begin{array}{c}0.5286^{*} \\
(0.0732)\end{array}$ & $\begin{array}{c}1.0000 \\
-\end{array}$ & & & & & & \\
\hline Feeder Cattle Cash & -0.1293 & -0.0143 & 1.0000 & & & & & \\
\hline & $(0.1327)$ & $(0.1360)$ & - & & & & & \\
\hline$\underline{\text { Live Cattle Cash }}$ & $\begin{array}{c}-0.0205 \\
(0.1589)\end{array}$ & $\begin{array}{c}-0.1355 \\
(0.1543)\end{array}$ & $\begin{array}{r}0.0254 \\
(0.1109)\end{array}$ & $\begin{array}{c}1.0000 \\
-\end{array}$ & & & & \\
\hline$\underline{\text { Corn Futures }}$ & $\begin{array}{c}0.9175^{*} \\
(0.0111)\end{array}$ & $\begin{array}{r}0.5214^{*} \\
(0.0716)\end{array}$ & $\begin{array}{c}-0.1337 \\
(0.1318)\end{array}$ & $\begin{array}{l}0.0130 \\
(0.1573)\end{array}$ & $\begin{array}{c}1.0000 \\
-\end{array}$ & & & \\
\hline$\underline{\text { Soybean Meal Futures }}$ & $\begin{array}{c}0.5087^{*} \\
(0.0782)\end{array}$ & $\begin{array}{r}\mathbf{0 . 9 7 2 2}^{*} \\
(0.0022)\end{array}$ & $\begin{array}{c}-0.0786 \\
(0.1323)\end{array}$ & $\begin{array}{c}-0.1402 \\
(0.1510)\end{array}$ & $\begin{array}{c}0.5077^{*} \\
(0.0759)\end{array}$ & $\begin{array}{c}1.0000 \\
-\end{array}$ & & \\
\hline Feeder Cattle Futures & $\begin{array}{c}-0.1705 \\
(0.1406)\end{array}$ & $\begin{array}{c}-0.0945 \\
(0.1524)\end{array}$ & $\begin{array}{c}0.3951^{*} \\
(0.0656)\end{array}$ & $\begin{array}{r}0.2075^{*} \\
(0.1041)\end{array}$ & $\begin{array}{c}-0.1285 \\
(0.1416)\end{array}$ & $\begin{array}{r}-0.0847 \\
(0.1511)\end{array}$ & $\begin{array}{c}1.0000 \\
-\end{array}$ & \\
\hline Live Cattle Futures & $\begin{array}{c}-0.0182 \\
(0.1615)\end{array}$ & $\begin{array}{c}-0.1391 \\
(0.1589)\end{array}$ & $\begin{array}{c}-0.0583 \\
(0.1096)\end{array}$ & $\begin{array}{c}\mathbf{0 . 6 3 8 7}^{*} \\
(0.0342)\end{array}$ & $\begin{array}{c}-0.0018 \\
(0.1598)\end{array}$ & $\begin{array}{c}-0.1317 \\
(0.1555)\end{array}$ & $\begin{array}{r}0.2959^{*} \\
(0.0965)\end{array}$ & $\begin{array}{c}1.0000 \\
-\end{array}$ \\
\hline
\end{tabular}

${ }^{2}$ Standard errors in parenthesis. 
Table 2. Regime 2 - Correlation Values ${ }^{2}$ for Feedlot Operation

\begin{tabular}{|c|c|c|c|c|c|c|c|c|}
\hline Regime 2 & Corn Cash & $\begin{array}{l}\text { Soybean } \\
\text { Meal } \\
\text { Cash }\end{array}$ & $\begin{array}{l}\text { Feeder Cattle } \\
\text { Cash }\end{array}$ & $\begin{array}{l}\text { Live } \\
\text { Cattle } \\
\text { Cash }\end{array}$ & $\begin{array}{l}\text { Corn } \\
\text { Futures }\end{array}$ & $\begin{array}{l}\text { Soybean } \\
\text { Meal Futures }\end{array}$ & $\begin{array}{l}\text { Feeder } \\
\text { Cattle } \\
\text { Futures }\end{array}$ & $\begin{array}{l}\text { Live Cattle } \\
\text { Futures }\end{array}$ \\
\hline$\underline{\text { Corn Cash }}$ & 1.0000 & & & & & & & \\
\hline$\underline{\text { Soybean Meal Cash }}$ & $\begin{array}{r}0.37547^{*} \\
(0.0654)\end{array}$ & $\begin{array}{c}1.0000 \\
-\end{array}$ & & & & & & \\
\hline Feeder Cattle Cash & $\begin{array}{c}-0.0918 \\
(0.0947)\end{array}$ & $\begin{array}{l}-0.0101 \\
(0.0966)\end{array}$ & $\begin{array}{c}1.0000 \\
-\end{array}$ & & & & & \\
\hline Live Cattle Cash & $\begin{array}{c}-0.0146 \\
(0.1129)\end{array}$ & $\begin{array}{c}-0.0962 \\
(0.1101)\end{array}$ & $\begin{array}{l}0.0180 \\
(0.0788)\end{array}$ & $\begin{array}{c}1.0000 \\
-\end{array}$ & & & & \\
\hline$\underline{\text { Corn Futures }}$ & $\begin{array}{c}\mathbf{0 . 6 5 1 6} \\
(0.0693)\end{array}$ & $\begin{array}{r}0.3703^{*} \\
(0.0642)\end{array}$ & $\begin{array}{c}-0.0949 \\
(0.0941)\end{array}$ & $\begin{array}{l}0.0092 \\
(0.1117)\end{array}$ & $\begin{array}{c}1.0000 \\
-\end{array}$ & & & \\
\hline$\underline{\text { Soybean Meal Futures }}$ & $\begin{array}{r}0.3613^{*} \\
(0.0674)\end{array}$ & $\begin{array}{r}\mathbf{0 . 6 9 0 4} \\
(0.0730)\end{array}$ & $\begin{array}{c}-0.0558 \\
(0.0941)\end{array}$ & $\begin{array}{c}-0.0996 \\
(0.1077)\end{array}$ & $\begin{array}{r}0.3606^{*} \\
(0.0660)\end{array}$ & $\begin{array}{c}1.0000 \\
-\end{array}$ & & \\
\hline$\underline{\text { Feeder Cattle Futures }}$ & $\begin{array}{c}-0.1211 \\
(0.1006)\end{array}$ & $\begin{array}{c}-0.0671 \\
(0.1085)\end{array}$ & $\begin{array}{c}0.2806^{*} \\
(0.0552)\end{array}$ & $\begin{array}{r}0.1474^{*} \\
(0.0756)\end{array}$ & $\begin{array}{c}-0.0912 \\
(0.1010)\end{array}$ & $\begin{array}{c}-0.0602 \\
(0.1075)\end{array}$ & $\begin{array}{c}1.0000 \\
-\end{array}$ & \\
\hline$\underline{\text { Live Cattle Futures }}$ & $\begin{array}{c}-0.0129 \\
(0.1147)\end{array}$ & $\begin{array}{c}-0.0988 \\
(0.1133)\end{array}$ & $\begin{array}{c}-0.0414 \\
(0.0779)\end{array}$ & $\begin{array}{r}\mathbf{0 . 4 5 3 6}{ }^{*} \\
(0.0537)\end{array}$ & $\begin{array}{c}-0.0013 \\
(0.1135)\end{array}$ & $\begin{array}{c}-0.0935 \\
(0.1109)\end{array}$ & $\begin{array}{r}0.2102^{*} \\
(0.0720)\end{array}$ & $\begin{array}{c}1.0000 \\
-\end{array}$ \\
\hline
\end{tabular}

${ }^{2}$ Standard errors in parenthesis. 
Table 3 Armach values - Feedlot Operation

\begin{tabular}{|c|c|c|c|c|c|c|c|c|}
\hline & \multicolumn{2}{|c|}{ Corn } & \multicolumn{2}{|c|}{ Soybean Meal } & \multicolumn{2}{|c|}{ Feeder Cattle } & \multicolumn{2}{|c|}{ Live Cattle } \\
\hline & Cash & Futures & Cash & Futures & Cash & Futures & Cash & Futures \\
\hline$\omega$ - omega & 0.3288 & $0.3761^{*}$ & $0.3594^{+}$ & $0.25598^{+}$ & 0.2870 & $0.1782^{*}$ & 0.2692 & $0.2807^{*}$ \\
\hline & $(0.2047)$ & $(0.1401)$ & $(0.1928)$ & $(0.1492)$ & $(0.1938)$ & $(0.0622)$ & $(0.1648)$ & $(0.0948)$ \\
\hline$\alpha \sim$ - alpha tilda & $0.5339^{*}$ & $0.4943^{*}$ & $0.5263^{*}$ & $0.5045^{*}$ & $0.4904^{*}$ & $0.5998^{*}$ & $0.7369^{*}$ & $0.7224^{*}$ \\
\hline & $(0.1479)$ & $(0.0871)$ & $(0.1103)$ & $(0.1703)$ & $(0.1374)$ & $(0.1342)$ & $(0.3634)$ & $(0.2180)$ \\
\hline$\beta$ - beta & 0.0758 & 0.0041 & 0.0719 & 0.2069 & 0.0167 & 0.0003 & 0.0001 & 0.0007 \\
\hline & $(0.4056)$ & $(0.2586)$ & $(0.3317)$ & $(0.3434)$ & $(0.4872)$ & $(0.2368)$ & $(0.5046)$ & $(0.2675)$ \\
\hline
\end{tabular}


Table 4 Average Hedge Ratios for Feedlot Operation ${ }^{3}$ - In Sample data

Average Hedge Ratio - RSDC Model - In Sample

$\begin{array}{clcccc} & \text { Corn } & \text { Soybean Meal } & \text { Feeder Cattle } & \text { Live Cattle } \\ \text { Regime 1 } & 0.4241 & 1.2753 & & 0.3318 & 0.7607 \\ & (0.0115) & (0.0119) & & (0.0164) & (0.0192) \\ \text { Regime 2 } & 0.4132 & 0.9221 & 0.1099 & 0.5206 \\ & (0.0081) & (0.0092) & (0.0115) & (0.0133) \\ \text { Min. Var. Comb. } & 0.4171 & 1.1015 & 0.2269 & 0.6394 \\ & (0.0100) & (0.0132) & (0.0141) & (0.0167)\end{array}$

Average Hedge Ratio - Single Hedge - In Sample

\begin{tabular}{|c|c|c|c|c|}
\hline & Corn & Soybean Meal & Feeder Cattle & Live Cattle \\
\hline \multirow{2}{*}{ Regime 1} & 0.3952 & 1.2643 & 0.3551 & 0.7170 \\
\hline & $(0.0120)$ & $(0.0117)$ & $(0.0151)$ & $(0.0191)$ \\
\hline \multirow[t]{2}{*}{ Regime 2} & 0.2806 & 0.8979 & 0.2522 & 0.5092 \\
\hline & $(0.0085)$ & $(0.0083)$ & $(0.0107)$ & $(0.0136)$ \\
\hline \multirow[t]{2}{*}{ Min. Var. Comb. } & 0.3361 & 1.0831 & 0.3021 & 0.6135 \\
\hline & $(0.0106)$ & $(0.0131)$ & $(0.0129)$ & $(0.0166)$ \\
\hline
\end{tabular}

${ }^{3}$ Standard errors in parenthesis. 
Table 5 Average Hedge Ratios for Feedlot Operation ${ }^{3}$ - Out of Sample data

Average Hedge Ratio - RSDC Model - Out of Sample

$\begin{array}{clccc} & \text { Corn } & \text { Soybean Meal } & \text { Feeder Cattle } & \text { Live Cattle } \\ \text { Regime 1 } & 0.4705 & 1.2979 & 0.4553 & 0.7309 \\ & (0.0166) & (0.0314) & (0.0348) & (0.0232) \\ \text { Regime 2 } & 0.4364 & 0.9579 & 0.2158 & 0.4947 \\ & (0.0101) & (0.0236) & (0.0231) & (0.0158) \\ \text { Min. Var. Comb. } & 0.4596 & 1.1415 & 0.3610 & 0.6206 \\ & (0.0139) & (0.0328) & (0.0341) & (0.0216)\end{array}$

\begin{tabular}{|c|c|c|c|c|}
\hline & Corn & Soybean Meal & Feeder Cattle & Live Cattle \\
\hline Regime 1 & 0.4458 & 1.2760 & 0.4577 & 0.6629 \\
\hline & $(0.0178)$ & $(0.0311)$ & $(0.0322)$ & $(0.0221)$ \\
\hline Regime 2 & 0.3166 & 0.9062 & 0.3251 & 0.4708 \\
\hline & $(0.0126)$ & $(0.0221)$ & $(0.0229)$ & $(0.0157)$ \\
\hline Min. Var. Comb. & 0.3891 & 1.1067 & 0.4056 & 0.5733 \\
\hline & $(0.0166)$ & $(0.0325)$ & $(0.0309)$ & $(0.0204)$ \\
\hline
\end{tabular}

${ }^{3}$ Standard errors in parenthesis. 
Table 6 Hedging Effectiveness - Feedlot Operation: In Sample data

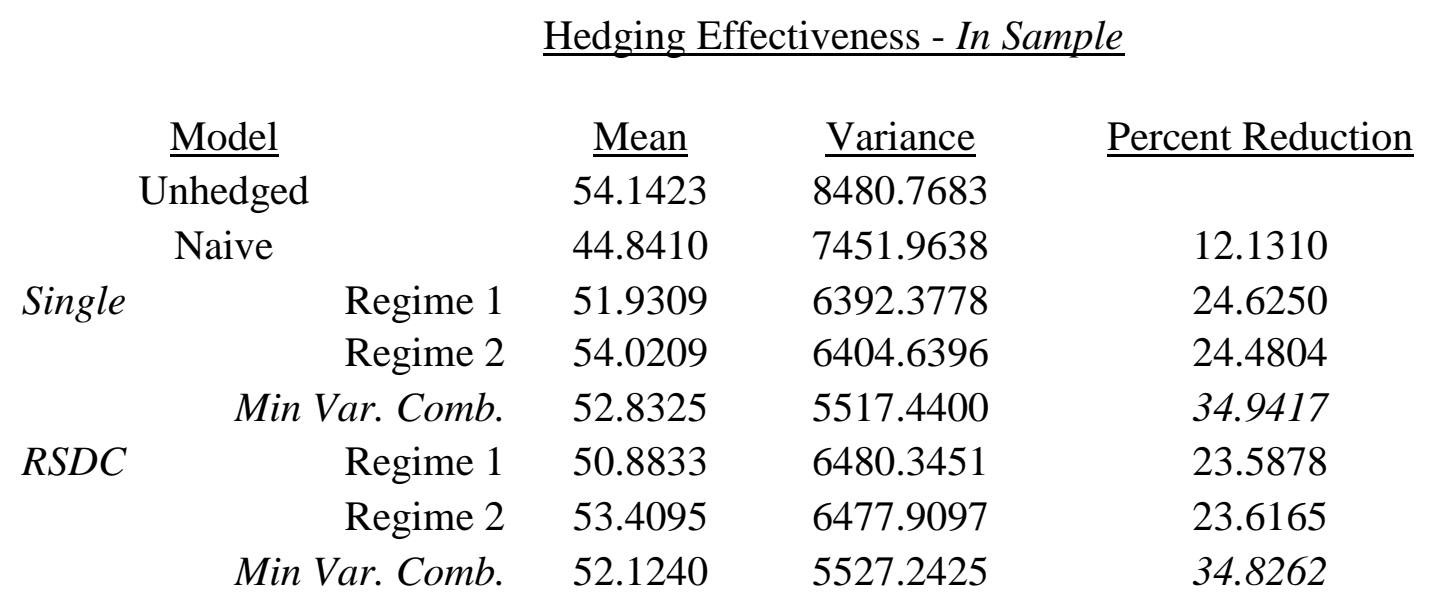


Table 7. Hedging Effectiveness - Feedlot Operation: Out of Sample data

$\underline{\text { Hedging Effectiveness - Out of Sample }}$

\begin{tabular}{|c|c|c|c|c|}
\hline \multicolumn{2}{|c|}{ Model } & Mean & Variance & Percent Reduction \\
\hline \multicolumn{2}{|c|}{ Unhedged } & 95.3895 & 7619.9329 & \\
\hline \multicolumn{2}{|c|}{ Naive } & 70.1029 & 4378.8699 & 42.5340 \\
\hline \multirow[t]{3}{*}{ Single } & Regime 1 & 75.6884 & 3786.8429 & 50.3035 \\
\hline & Regime 2 & 81.3983 & 4234.0453 & 44.4346 \\
\hline & Min Var. Comb. & 78.0494 & 3252.5224 & 57.3156 \\
\hline \multirow[t]{3}{*}{$R S D C$} & Regime 1 & 74.8222 & 3695.1007 & 51.5074 \\
\hline & Regime 2 & 80.8219 & 4098.9267 & 46.2078 \\
\hline & Min Var. Comb. & 77.5238 & 3062.8159 & 59.8052 \\
\hline
\end{tabular}

